\title{
In Situ TEM and Synchrotron Characterization of U-10Mo Thin Specimen Annealed at the Fast Reactor Temperature Regime
}

\author{
Di Yun ${ }^{1,2}$, Kun Mo ${ }^{1}$, Walid Mohamed ${ }^{1}$, Bei Ye ${ }^{1}$, Marquis A. Kirk ${ }^{1}$, Peter \\ Baldo $^{1}$, Ruqing Xu ${ }^{1}$, Abdellatif M. Yacout ${ }^{1}$ \\ ${ }^{1}$ Argonne National Laboratory \\ 9700 South Cass Avenue, Argonne, IL 60439 \\ ${ }^{2}$ Xi'an Jiao Tong University \\ 28 Xian Ning West Road, Xi'an, China, 710049, diyun1979@xjtu.edu.cn
}

\begin{abstract}
U-Mo metallic alloys have been extensively used for the Reduced Enrichment for Research and Test Reactors (RERTR) program, which is now known as the Office of Material Management and Minimization under the Conversion Program. This fuel form has also recently been proposed as fast reactor metallic fuels in the recent DOE Ultra-high Burnup Fast Reactor project. In order to better understand the behavior of U-10Mo fuels within the fast reactor temperature regime, a series of annealing and characterization experiments have been performed.
\end{abstract}

Annealing experiments were performed in situ at the Intermediate Voltage Electron Microscope (IVEM-Tandem) facility at Argonne National Laboratory (ANL). An electro-polished U-10Mo alloy fuel specimen was annealed in situ up to $700{ }^{\circ} \mathrm{C}$. At an elevated temperature of about $540{ }^{\circ} \mathrm{C}$, the U-10Mo specimen underwent a relatively slow microstructure transition. Nano-sized grains were observed to emerge near the surface. At the end temperature of $700{ }^{\circ} \mathrm{C}$, the nearsurface microstructure had evolved to a nano-crystalline state. In order to clarify the nature of the observed microstructure, Laue diffraction and powder diffraction experiments were carried out at beam line 34-ID of the Advanced Photon Source (APS) at ANL. Phases present in the as-annealed specimen were identified with both Laue diffraction and powder diffraction techniques. The U$10 \mathrm{Mo}$ was found to recrystallize due to temperature-induced recrystallization 
driven by a high density of pre-existing dislocations. A separate in situ annealing experiment was carried out with a Focused Ion Beam processed (FIB) specimen. A similar microstructure transition occurred at a lower temperature of about $460{ }^{\circ} \mathrm{C}$ with a much faster transition rate compared to the electro-polished specimen.

\section{INTRODUCTION}

U-Mo metallic alloys have been extensively used for the Reduced Enrichment for Research and Test Reactors (RERTR) program, which is now known as the Office of Material Management and Minimization under the Conversion Program, as research and test reactor fuels [1-5]. These fuels are in forms of either monolithic plates or dispersion plates in which U-Mo fuel particles are embedded in Aluminum cladding. Moreover, U-Mo alloys have been proposed as metallic fuel candidates for fast reactors due to their ideal thermal properties [6]. More recent efforts also investigated the behavior of these alloys along with $\mathrm{U}-\mathrm{Zr}$ alloys under fast reactor irradiation conditions [7]. Currently, irradiation efforts are coordinated through the advanced fuels campaign (AFC) to test both solid (cylindrical) and annular U-Mo and U-Zr alloy fuels for fast reactor applications. Although the microstructure and behavior of U-Mo fuel particles under irradiations in dispersion fuels have been quite extensively investigated with transmission electron microscopy (TEM) at the RERTR temperature regime (usually no higher than $200{ }^{\circ} \mathrm{C}$ ) $[8,9]$, the behaviors of monolithic U-Mo alloys at higher temperatures are not well understood at this microscale level. In order to qualify U-Mo alloy fuels for fast reactor application, a systematic and thorough evaluation of the fuel behaviors at fast reactor operation conditions is necessary. As fuel performance is a very complex matter that couples many correlated phenomena, separate effect studies become important to help understand and interpret fuel behaviors. Experimental techniques such as TEM can be utilized as effective tools to provide microscopic 
insights to such separate effects such as temperature or irradiation effects. Operation of metallic alloy fuels under fast reactor conditions couples many different phenomena such as redistribution of constituents, release of fission induced noble gas, swelling caused by gaseous and solid fission fragments and porosity induced changes in thermal conductivity, etc. The focus of this work, however, is on the recrystallization of the fuel at the fast reactor temperature regime.

Recrystallization is a phenomenon of great technological importance in many metals, including metallic nuclear fuels. U-Mo alloy fuels were observed to go through a recrystallization process at the relatively low operating temperatures of research and test reactors [10]. Thermally-driven recrystallization is widely observed in cold-worked metals where high density of dislocations serves as a driving force for the phenomenon [11]. Whether recrystallization will happen in U-Mo alloy fuels at the fast reactor temperature regime remains at question due to the lack of experimental data.

In this work, in situ transmission electron microscopy (TEM) annealing experiments were performed to characterize the microstructure of U-10Mo (depleted uranium with 10wt.\% Mo) alloy fuel specimens up to a temperature of $700{ }^{\circ} \mathrm{C}$, which is in the fast reactor temperature regime. Intriguing microstructure evolutions related to recrystallization were observed during the annealing process. Through Laue diffraction and powder diffraction experiments, microstructure near the annealed specimen surface was identified as nanometer-sized $\mathrm{UO}_{2}$ and $\mathrm{UN}$ grains which were due to interaction between the U-Mo alloy and residual air together with nanometer-sized U-Mo grains. The reduced grain size of the U-10Mo $\gamma$ phase was the result of a thermallyinduced recrystallization due to a high density of pre-existing dislocations. This observation provides useful insight into possible processes that may lead to 
recrystallization in U-Mo metallic alloy fuels in the fast reactor temperature regime.

\section{EXPERIMENTAL}

The original monolithic U-10Mo thin plates coated with zirconium were received from a group within ANL. The alloy was cast into coupon shaped ingots using a graphite mold. The alloy coupon had an approximate dimension of $80.2 \mathrm{~mm} \times 45.6 \mathrm{~mm} \times 3 \mathrm{~mm}$. The carbon content of this alloy coupon was about $1000 \mathrm{ppm}$. This ingot was first acid cleaned using a mixture of nitric and hydrofluoric acid and then laminated, in a carbon steel can, using pure $\mathrm{Zr}$ (99.9\% pure) foil with approximate starting thickness of $150 \mu \mathrm{m}$, on each surface. The Zr-laminated U-10Mo coupon was pre-heated at $650^{\circ} \mathrm{C}$ for $30 \mathrm{~min}$ in a furnace, and then corolled to a thickness of approximately $0.5 \mathrm{~mm}$. A postrolling annealing treatment was performed at $650^{\circ} \mathrm{C}$ for $45 \mathrm{~min}$. The annealed foil was then removed from the can, and cold-rolled to the final thickness of $0.4 \mathrm{~mm}$. This thickness includes the $\mathrm{Zr}$ diffusion barrier layer on each surface. The final thickness of $\mathrm{Zr}$ diffusion barrier was approximately 25 $\mu \mathrm{m}$. The final as-rolled U-Mo foil was then sheared into mini-size foils.

Pre-thinned disc specimens were prepared by mechanically thinning and polishing of the monolithic U-10Mo thin foils to remove the zirconium coating, followed by disc punching with a standard $3 \mathrm{~mm}$ disc punch. The mechanical thinning, which reduced the foil thickness from about $0.4 \mathrm{~mm}$ to about $50 \mu \mathrm{m}$, was followed by electro-jet-polishing until perforation to produce TEM specimens. The electrolyte used in this polishing step was 5 vol.\% perchloric acid in methanol solution. The electrolyte was used at a temperature of $-40{ }^{\circ} \mathrm{C}$ for the perforation of the TEM specimens. Measurements of grain sizes were performed via TEM. Due to availability of electron transparent thin areas, only a few grains were measured. The average grain size is about $3 \mu \mathrm{m}$, which is 
smaller than the typical grain size of U-10Mo monolithic foils [12, 13]. This is partially due to the lack of annealing after the cold rolling of the foil.

One of the pre-thinned TEM specimen was then annealed and examined in situ at the IVEM-Tandem facility at ANL in a vacuum of about $1 \times 10^{-7}$ Torr. The specimen was heated from room temperature to $700{ }^{\circ} \mathrm{C}$. Intermittent stops at 126 ${ }^{\circ} \mathrm{C}$ and $602{ }^{\circ} \mathrm{C}$ were taken to capture static TEM images and diffraction patterns while the continuous evolution of the microstructure was digitally recorded over the course of the annealing process. The specimen was then gradually cooled down to room temperature by slowly decreasing the power of the heating element.

After the in situ observation of the annealing process at the IVEM, synchrotron radiation experiments were carried out at beam line 34-ID of the Advanced Photon Source (APS) of ANL [14]. Micro-beam Laue diffraction was conducted with a white $\mathrm{x}$-ray beam focused to $0.6 \mu \mathrm{m} \times 0.4 \mu \mathrm{m}$ in size by a pair of Kirkpatrick-Baez mirrors. The white beam contained photons with energy from $7 \mathrm{keV}$ to $30 \mathrm{keV}$. Laue diffraction patterns were collected in reflection geometry with 45 incident angle with respect to sample surface normal, and with a Perkin-Elmer XRD1621 area detector placed near $90^{\circ}$ diffraction angle over the sample at a distance of $510 \mathrm{~mm}$. Laue diffraction data was obtained for both the very thin part of the specimen (near perforated area) and the thicker part of the specimen (further away from the perforated area). After the Laue patterns were indexed, X-ray beam was switched to monochromatic mode by introducing a $\mathrm{Si}(111)$ double-crystal monochromator into the beam; this allows lattice dspacing for selected reflections in the Laue patterns be determined through $\mathrm{X}$ ray energy scans. X-ray powder diffraction was performed with a much broader $(50 \mu \mathrm{m} \times 50 \mu \mathrm{m})$, unfocused $27 \mathrm{keV}$ monochromatic beam; diffraction patterns were collected with a MAR $165 \mathrm{CCD}$ detector in the forward direction 
downstream to the sample. Powder diffraction data was also obtained for both the thin and thicker parts of the specimen.

\section{RESULTS AND DISCUSSION}

Micrographs in Fig. 1 show the starting (pre-annealing) microstructure of the U-10Mo thin specimen along with the corresponding electron diffraction pattern. Using only the $300 \mathrm{keV}$ electron beam from the IVEM, and without the influence of ion irradiation and temperature, mobility of high density dislocations was observed (see video 1 for example). Streaking of the diffraction spots was observed under the e-beam-only condition. Those observations are illustrated with the selected area electron diffraction (SAED) pattern shown in Fig. 2, where Fig. 2 (a) was taken at room temperature at the earliest occasion during the TEM session, and Fig. 2 (b) was taken approximately 15 minutes later, after the observations of dislocation motions. A possible explanation for the streaking of diffraction spots is the oxidation of specimen surface. At the beginning of the examination, a ring-like diffraction pattern formed inside the lowest index (110) diffraction spots of the body centered cubic (bcc) $\gamma \mathrm{U}-10 \mathrm{Mo}$, which is a reflection of surface oxidation. This ring became clearer in Fig. 2 (b) and is consistent with oxidized phase $\mathrm{UO}_{2}$. More distinct diffraction spots and surface particles of $\mathrm{UO}_{2}$ have been identified by Van den Berghe et al. [4]. Surface oxidation of the specimen was due to residual air (mainly oxygen and nitrogen) in the vacuum of the IVEM electron beam column, as well as specimen contact with air during transportation to the IVEM facility after the electro-polishing. Uranium nitride (UN) was also found in the specimen surface. The oxidized particles in this experiment might have caused the underlying UMo crystallites to be strained as to induce further streaking of the diffraction spots. 
As shown in Fig. 2, there is streaking of diffraction spots from both SAED patterns which, at these extents, are usually indicators of a high defect density. The streaking observed under this circumstance, without ion irradiation or any perceivable irradiation effects, is a confirmation of the observed high density of dislocations in the bcc $\gamma \mathrm{U}-10 \mathrm{Mo}$ matrix. These observations are in agreement with earlier received information that rather high residual stresses were observed in the as-fabricated RERTR monolithic mini-plates [15].

In situ heating was performed at a heating rate of about $15^{\circ} \mathrm{C}$ per minute. Heating was stopped at around $126^{\circ} \mathrm{C}$, when surface oxidation build-up and contamination rendered TEM examination nearly impossible. The TEM characterization was then moved to another area not previously under the ebeam where oxidation build-up was not as significant. This suggests that oxidation is accelerated under the electron beam. Further oxidation of the surface was observed under the e-beam at a much slower rate indicating that the residual air content decreased after the initial oxidation of the earlier region, and that the TEM vacuum was well insulated. The SAED pattern taken at $126{ }^{\circ} \mathrm{C}$ is shown in Fig. 3. It can be clearly seen that the streaking of the diffraction spot became more significant, as many additional distinct diffraction spots appear along the streaked arc. Several distinct spots seemed to form around the diffusive ring pattern of the $\mathrm{UO}_{2}$ phase, indicating preferred orientation of surface oxide particles. These diffraction spots are consistent with those observed by Van den Berghe et al. [4]. Several distinct oxide diffraction rings are indexed in Fig. 3.

The specimen was further heated to $602{ }^{\circ} \mathrm{C}$ at a higher heating rate of about $35^{\circ} \mathrm{C}$ per minute. No dislocation motion was observed until the specimen reached about $540^{\circ} \mathrm{C}$. Starting from about $540^{\circ} \mathrm{C}$, another type of microstructure change became apparent. Very small particles with sizes in the nanometer range were observed to form. The heating was stopped at $602{ }^{\circ} \mathrm{C}$, when static TEM 
images were taken. Fig. 4 (a) and (b) show the bright field TEM image and its corresponding SAED pattern, respectively, taken at $602{ }^{\circ} \mathrm{C}$. The long streaking in the SAED (Fig. 4 (b)) is closer to a complete diffraction ring. Such pattern evolution suggests that the U-Mo matrix near the surface might have evolved towards a microstructure close to nano-crystalline (assuming the particles reflect crystal orientation changes) or second phase particle separation (local phase decomposition). The remaining strong diffraction spots suggest that these formed crystallites or second phase particles are likely near the surface, whereas the bulk U-Mo remained in its earlier orientation and retained its main phase.

As a final heating step, the specimen was heated to a temperature of $700{ }^{\circ} \mathrm{C}$, which was the highest temperature that the double-tilt heating stage was capable of reaching. As oxidation had nearly completely stopped, the TEM observation region was not moved further. Fig. 5 (a) and (b) show the bright field TEM image and its corresponding SAED pattern, respectively, taken at $700{ }^{\circ} \mathrm{C}$. Several relatively big particles were marked with arrows in Fig. 5 (a). The overall particle size distribution was determined by collecting large quantity of measurements (more than 200 objects were measured on TEM micrographs) on the particle sizes and the average particle size was found to be $20.1 \pm 5.7 \mathrm{~nm}$, as shown in Fig. 6. The SAED pattern shown in Fig. 5 (b) exhibits characteristics that are, again, close to nano-crystalline materials (crystallite particles) or second phase particles.

It should be noted that these microstructures identified as nano-crystallite particles or second phase particles appear quite like dislocation loops. However, the in situ observation showed rather quick contrast change of these features (see video 2 for example), too quick to reflect bending effects if these features were dislocation loops. It is possible that the stored strain energy inside the specimen caused a thermally-driven re-crystallization. The thermally-driven recrystallization was observed earlier with metals but only resulted in micrometer 
sized crystallites [16]. The physics behind the formation of such small crystallite particles and both possibilities of these particles being nano-crystallites or new phase precipitates therefore need to be further explored.

In order to further clarify the nature of these observed microstructures, synchrotron X-ray radiation techniques were applied to characterize both an asprepared specimen and the as-annealed specimen. Laue diffraction was first applied to characterize the phases in the as-annealed specimen. Fig. 7 (a) shows the X-ray diffraction from white beam followed by monochromatic beam, indicating formation of a $\mathrm{UO}_{2}$ phase at the very thin area of the TEM specimen. The square symbols show where oxide diffraction peaks were found that match the expected $\mathrm{UO}_{2}$ diffraction pattern. Many of these peaks have been indexed as shown in the figure. Fig. 7 (b) shows diffraction from white beam followed by monochromatic beam indicating that the bcc $\gamma \mathrm{U}-10 \mathrm{Mo}$ was dominant in the specimen bulk. An important conclusion from this Laue diffraction characterization is that neither $\mathrm{U}_{2}$ Mo nor $\alpha-\mathrm{U}$ phases were identified in the specimen. This finding points to the direction that excludes the possibility of the observed microstructures being phase-decomposed particles (precipitates).

Powder diffraction technique (with a transmission geometry) was also used in order to significantly enhance the q-space resolution. In addition, powder diffraction technique is more capable of picking up small volume of minor phases than Laue diffraction. A series of powder diffraction patterns were obtained as the beam was scanned from the thin part of the specimen to the thicker part of the specimen. Fig. 8 shows the powder diffraction pattern from a location about $50 \mu \mathrm{m}$ from the perforated area. A selected indexing of this powder diffraction pattern is provided in Fig. 9, where the bcc $\gamma \mathrm{U}-10 \mathrm{Mo}, \mathrm{UO}_{2}$, and UN phases were identified. It can be seen that the signal levels at the $\mathrm{q}$ locations where $\mathrm{U}_{2} \mathrm{Mo}$ or $\alpha-\mathrm{U}$ diffraction peaks are expected are not significantly higher than noise levels. This further demonstrated that no $\mathrm{U}_{2} \mathrm{Mo}$ or 
$\alpha$-U phases (lower ticks in Fig. 9) are present in the as-annealed specimen. In addition, had there been a phase decomposition, large volume of $\mathrm{U}_{2} \mathrm{Mo}$ and $\alpha$-U would have been seen. It is therefore concluded that the observed microstructures which emerged after heating to $540{ }^{\circ} \mathrm{C}$ are near-surface nanograin re-crystallized crystallites. The exact driving force of the recrystallization process to produce crystallites that are of nano-meter sizes, however, is not entirely clear at this moment.

One possible driving force is the high density of dislocations in the specimen combined with the free surfaces of the TEM thin specimen. Powder diffraction line profiles from the as-annealed specimen and an as-prepared specimen were compared (see Fig. 10). Again, powder diffraction data from a location about $50 \mu \mathrm{m}$ from the perforated area of the as-annealed specimen was used. Peak broadening was observed in the as-annealed specimen (Fig. 10 (inset)). The (110) bec $\gamma$ U-10Mo peak full width at half maximum (FWHM) is seen to increase from 0.026 angstroms to 0.035 angstroms. As the recrystallization process is known to reduce dislocation and point defect density within the recrystallized grain, this observed increase in the FWHM must be associated with the decrease of grain size. Through careful analyses of TEM micrographs of the as-annealed specimen, new grain boundaries have been identified indicating grain subdivision or recrystallization of the underlying bulk U-Mo grains. It is then determined that the high pre-existing dislocation density has led to a bulk recrystallization upon annealing.

Another TEM annealing experiment was performed on a specimen processed with a focused ion beam (FIB). Fig. 11 shows the TEM micrograph of the FIB-processed specimen. As the FIB technique induces extensive surface damage, it is believed that near the specimen surface the density of dislocations in the as-FIBed specimen is much higher than that of the electro-polished specimen. In situ annealing was performed on this specimen at the IVEM 
facility as well. Due to technical issues, video could not be recorded for this annealing experiment. At about $460{ }^{\circ} \mathrm{C}$, the as-FIBed specimen underwent a similar microstructure change as that observed in the electro-polished specimen. However, the transition into a nano-grain microstructure happened at a much faster rate: in less than a minute, the near surface microstructure of the as-FIBed specimen became nano-grain, as evidenced by Fig. 12. It is decided that the higher dislocation density provided the driving force for the quicker microstructure transition at a lower temperature. This fits well within the theory of thermally-driven re-crystallization $[11,17]$.

From the above described experimental observations, an important implication can be drawn: U-10Mo metallic fuel undergoes thermally driven recrystallization at the fast reactor temperature regime when high dislocation density provides the driving force. Inside the metallic fuels of an operating reactor, dislocation accumulates as a result of irradiation damage. This will likely supply the driving force needed for such recrystallization to occur.

\section{CONCLUSION}

TEM annealing experiments were performed in situ at the IVEM-Tandem facility at Argonne National Laboratory (ANL). An electro-polished U-10Mo alloy fuel specimen was annealed in situ up to $700{ }^{\circ} \mathrm{C}$. At room temperature, a high density of dislocations was observed. Under the influence of the electron beam only, the surface of the specimen underwent oxidation. Streaking of the diffraction spots was clearly observed. At an elevated temperature of about 540 ${ }^{\circ} \mathrm{C}$, the U-10Mo specimen went through a relatively slow microstructure transition. Nano-sized grains were observed to emerge. At the end temperature of $700{ }^{\circ} \mathrm{C}$, the near surface microstructure had evolved to a state near nanocrystalline material. 
Laue diffraction with a micro beam showed that $\mathrm{UO}_{2}$ phase exists as a significant phase in the thin area near the perforation of the as-annealed TEM specimen, whereas the U-10Mo $\gamma$ phase dominated in the thicker part of the specimen. It was also determined, together with the powder diffraction technique, that neither $\mathrm{U}_{2}$ Mo nor $\alpha$-U phases were present in the as-annealed specimen, excluding the possibility of a phase decomposition. $\mathrm{UO}_{2}, \mathrm{UN}$ and $\mathrm{U}$ 10 Mo $\gamma$ phases were identified as the only phases present in the as-annealed specimen. Through TEM and powder diffraction characterizations, it was determined that the bcc $\gamma$ U-10Mo recrystallized to become nanometer-sized crystallites near the specimen surface, probably due to a combined driving force of the pre-existing high dislocation density and free surfaces of the thin TEM specimen.

A separate in situ annealing experiment was carried out with a specimen processed with FIB. Due to the extensive ion-beam-induced surface damage and the resulting high dislocation density, a similar microstructure transition occurred at a lower temperature of about $460{ }^{\circ} \mathrm{C}$ with a much faster microstructure transition. This fits well with the theory of the thermally activated re-crystallization.

\section{ACKNOWLEDGMENTS}

The authors would like to thank Javier Figueroa from ANL for providing the original materials for this work, and Dr. Bo Yao for preparing the FIBprocessed specimen. The authors are also grateful for the many useful discussions with Dr. G. L. Hofman and Dr. J. Rest from ANL regarding the scientific observations. The authors are particularly grateful for Dr. Jian Gan for his comments on this work. This work was supported under US Department of Energy Contract DE-AC02-06CH11357. 


\section{REFERENCES}

1. A. Leenaers, S. Van den Berghe, E. Koonen, C. Jarousse, F. Huet, M. Trotabas, M. Boyard, S. Guillot, L. Sannen, M. Verwerft, Postirradiation Examination of Uranium-7wt\% Molybdenum Atomized Dispersion Fuel, Journal of Nuclear Materials 335 (2004) 39-47.

2. H-Y. Chiang, T. Zweifel, H. Palancher, A. Bonnin, L. Beck, P. Weiser, M. DÖblinger, C. Sabathier, R. Jungwirth, W. Petry, Evidence of Amorphous Interdiffusion Layer in Heavy Ion Irradiated U$8 \mathrm{wt} \% \mathrm{Mo} / \mathrm{Al}$ Interfaces, Journal of Nuclear Materials 440 (2013) 117123.

3. J. Gan, D.D. Keiser, B.D. Miller, D.M. Wachs, T.R. Allen, M.A. Kirk, J. Rest, Microstructure of RERTR DU-alloys irradiated with krypton ions up to $100 \mathrm{dpa}$, Journal of Nuclear Materials 411 (2011) 174-180.

4. S. Van den Berghe, W. Van Renterghem, A. Leenaers, Transmission electron microscopy investigation of irradiated U-7wt\%Mo dispersion fuel, Journal of Nuclear Materials 375 (2008) 340-346.

5. S. Van den Berghe, Y. Parthoens, G. Cornelis, A. Leenaers, E. Koonen, V. Kuzminov, C. Detavernier, Swelling of U(Mo) Dispersion Fuel Under Irradiation - Non-destructive Analyses of the SELENIUM plates, Journal of Nuclear Materials 442 (2013) 60-68.

6. B. KRYGER, "Contribution to the study of the Fission-Gas release in metallic nuclear fuels," Doctoral Dissertation, Conservatoire National des Arts et Métiers, October, 1969.

7. A. E. Wright, H. J. Chichester, S. L. Hayes, T. K. Kim, Y. S. Kim, R. D. Mariani, W. D. Pointer, A. M. Yacout, and D. Yun, "Development of Advanced Ultra-High Burnup SFR Metallic Fuel Concept - Project Overview," Proceedings of Nuclear Fuels and Structural Materials for the Next Generation Nuclear Reactors (NFSM), embedded topical 
meeting of 2012 American Nuclear Society (ANS) Annual Meeting, Chicago, IL, June 24-28, 2012.

8. J. Gan, D. D. Keiser Jr., D.D. Keiser Jr., B.D. Miller, A.B. Robinson, J.F. Jue, P. Medvedev, D.M. Wachs, "TEM characterization of U7Mo/Al-2Si dispersion fuel irradiated to intermediate and high fission densities”. Journal of Nuclear Materials, 407, 48-54, (2010).

9. A. Leenaers, S. Van den Berghe, W. Van Renterghem, F. Charollais, P. Lemoine, C. Jarousse, A. Röhrmoser, W. Petry, "Irradiation behavior of ground U(Mo) fuel with and without Si added to the matrix," Journal of Nuclear Materials, 412, 41-52, (2011).

10. Y. S. Kim, G. L. Hofman, J. S. Cheon, "Recrystallization and fissiongas-bubble swelling of U-Mo fuel," Journal of Nuclear Materials 436, 14-22, (2013).

11. F. J. Humphreys, M. Hatherly, "Recrystallization and Related Annealing Phenomena," $2^{\text {nd }}$ Edition, Elsevier, (2004).

12. J-F. Jue, D. D. Keiser, C. R. Breckenridge, G. A. Moore, M. K. Meyer, "Microstructural characteristics of HIP-bonded monolithic nuclear fuels with a diffusion barrier," Journal of Nuclear Materials, 448, (2014) 250-258.

13. J-F. Jue, T. L. Trowbridge, C. R. Breckenridge, G. A. Moore, M. K. Meyer, D. D. Keiser, "Effects of heat treatment on U-Mo fuel foils with a zirconium diffusion barrier," Journal of Nuclear Materials, 460, (2015), 153-159.

14. W. Liu, P. Zschack, J. Tischler, G. Ice, B. Larson, "X-ray Laue Diffraction Microscopy in 3D at the Advanced Photon Source," 10th International Conference on X-ray Microscopy, I. McNulty, C. Eyberger, B. Lai, eds., 1365, AIP, (2011), 108 - 111. 
15. D. W. Brown, M. A. Okuniewski, J. D. Almer, L. Balogh, B. Clausen, J. S. Okasinski, B. H. Rabin, "High energy X-ray diffraction measurement of residual stresses in a monolithic aluminum clad uranium-10 wt\% molybdenum fuel plate assembly," Journal of Nuclear Materials 441, 252-261, (2013).

16. A.D. Rollett, M. De Graef, "Re-crystallization, Theory and Practices," http://neon.mems.cmu.edu/rollett/27301/L_suppl_Rex_Sep06.pdf

17. T. S. Srivatsan, "Relationship between annealing and recrystallization in an aluminum-lithium alloy," Journal of Materials Science Letters 6 (1987) 948-950. 
Fig. 1. (a) Bright field micrograph of U-10Mo TEM specimen at a magnification of $30 \mathrm{~K}$ at room temperature showing high initial density of dislocations and (b) the corresponding dark field micrograph of the same area

Fig. 2. (a) SAED pattern acquired at room temperature at an earliest occasion during the TEM session and (b) SAED pattern acquired about 15 minutes after the first SAED pattern was taken

Fig. 3. SAED pattern acquired at $126^{\circ} \mathrm{C}$ at the same location as that in Fig. 2 (b), with several $\mathrm{UO}_{2}$ diffraction rings indexed

Fig. 4. Bright field TEM image (a) and its corresponding SAED pattern (b) at a new location at $602{ }^{\circ} \mathrm{C}$

Fig. 5. Bright field TEM image (a) and its corresponding SAED pattern (b) at $700^{\circ} \mathrm{C}$

Fig. 6. Measured particle (crystallite or phase particles) size distribution observed by TEM at $700{ }^{\circ} \mathrm{C}$

Fig. 7. Laue diffraction analyses of the main phases present in the as annealed $\mathrm{U}-10 \mathrm{Mo}$ specimen (a) indexing of the $\mathrm{UO}_{2}$ phase and (b) indexing of the $\mathrm{U}$ $10 \mathrm{Mo} \gamma$-phase

Fig. 8. Powder diffraction pattern of the as-annealed U-10Mo specimen

Fig. 9. Indexing of selected peaks of the powder diffraction of the as annealed U-10Mo specimen

Fig. 10. Comparison of powder diffraction line profiles between the as-annealed $\mathrm{U}-10 \mathrm{Mo}$ specimen and an as-prepared U-10Mo TEM specimen

Fig. 11. TEM micrograph of the as-FIBed U-10Mo specimen. (Insert shows the corresponding SAED diffraction pattern along the $\left[\begin{array}{lll}0 & 0 & 1\end{array}\right]$ zone axis)

Fig. 12. TEM micrograph of the nano-grain microstructure at $460{ }^{\circ} \mathrm{C}$ for the asFIBed U-10Mo specimen. (Insert shows the corresponding SAED diffraction pattern) 


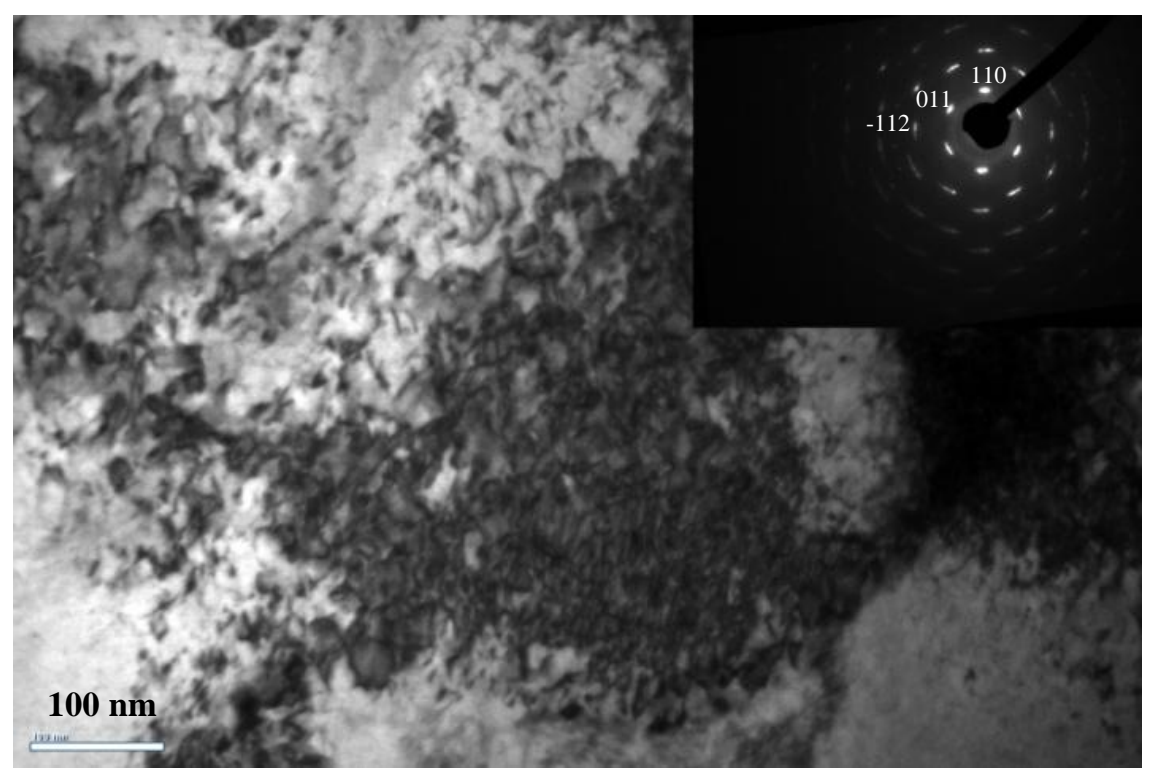

(a)

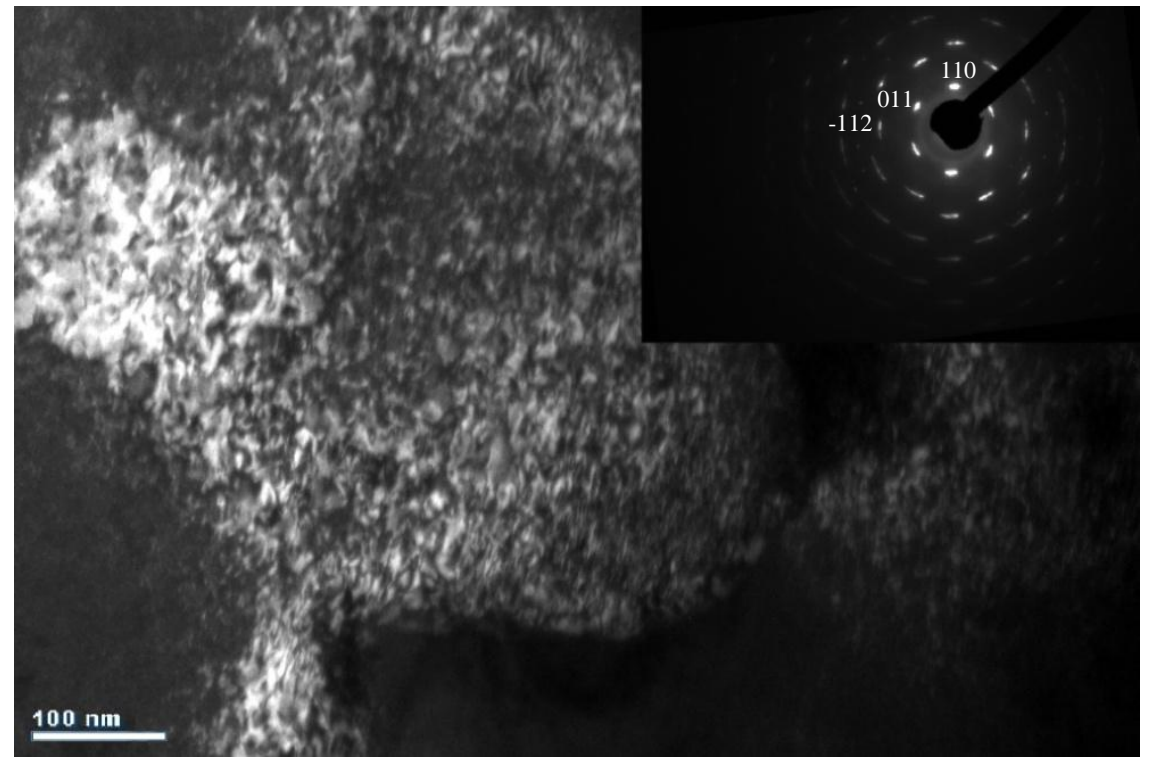

(b)

Figure 1 


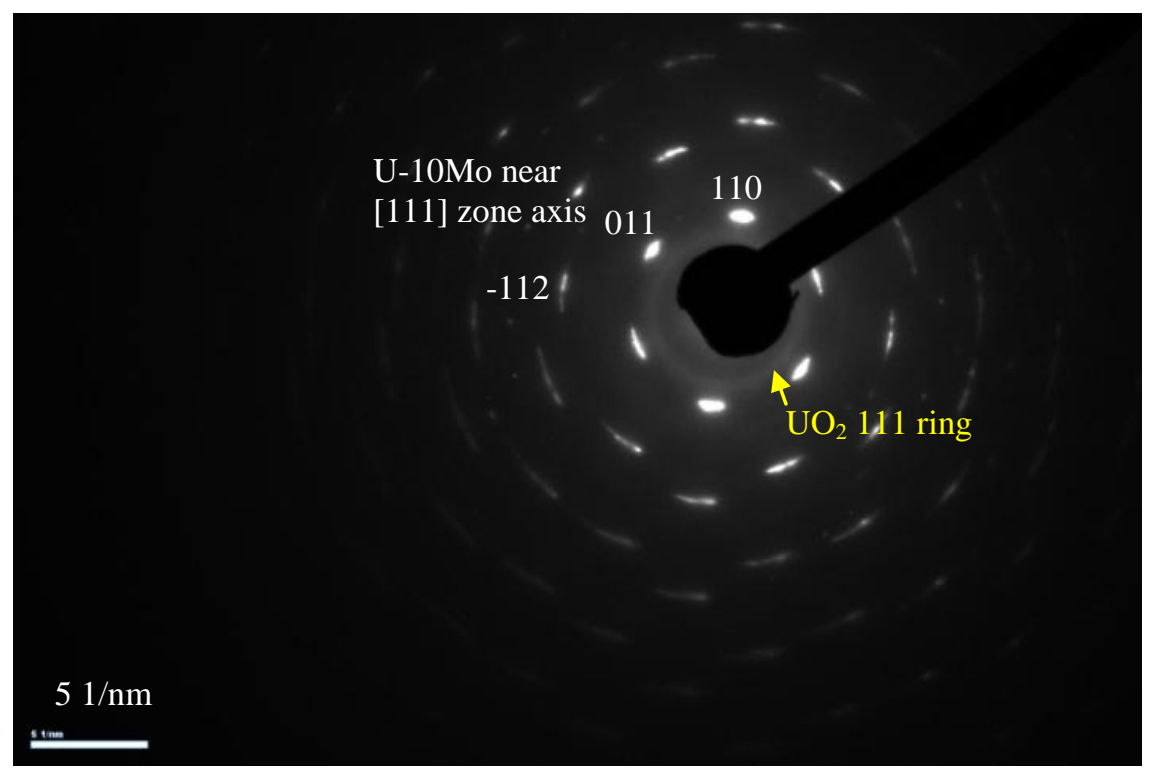

(a)

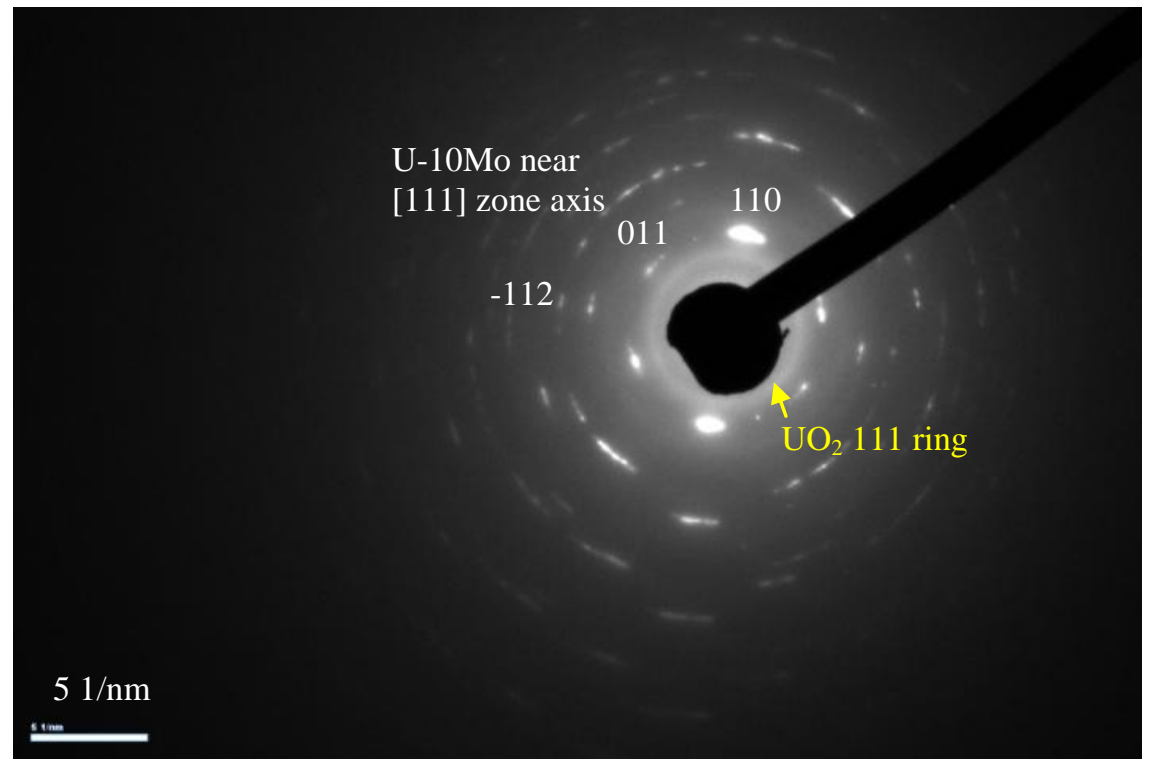

(b)

Figure 2. 


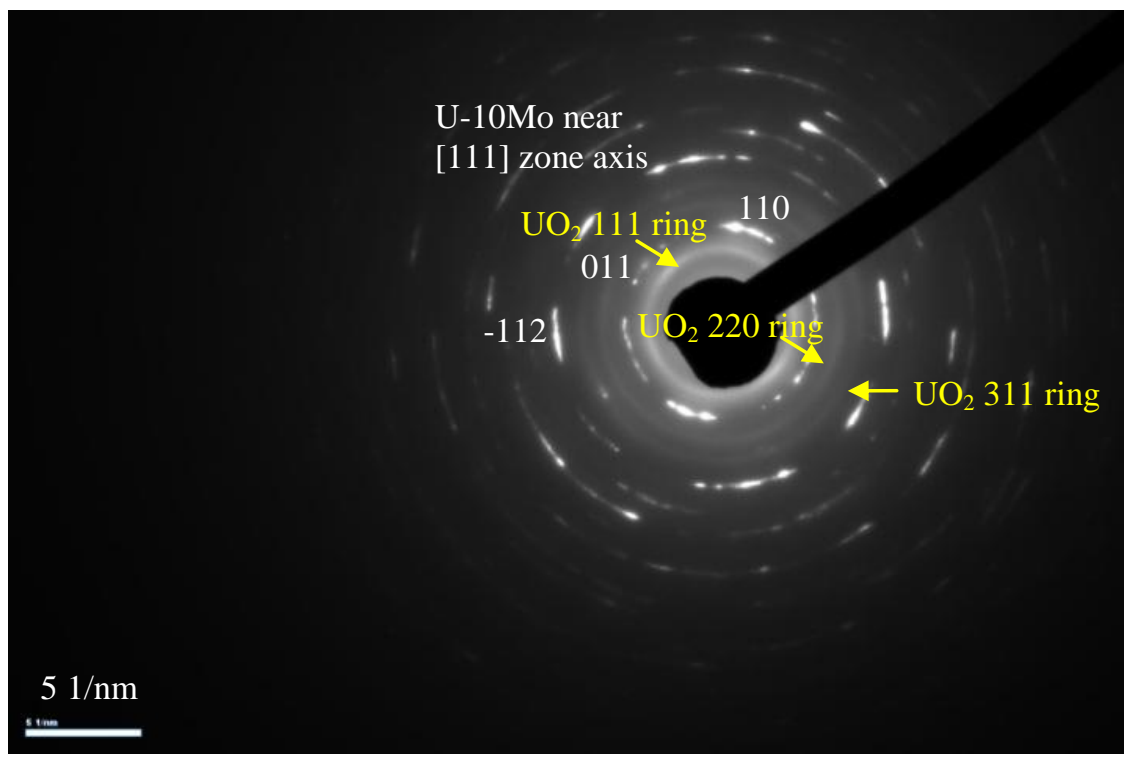

Figure 3. 


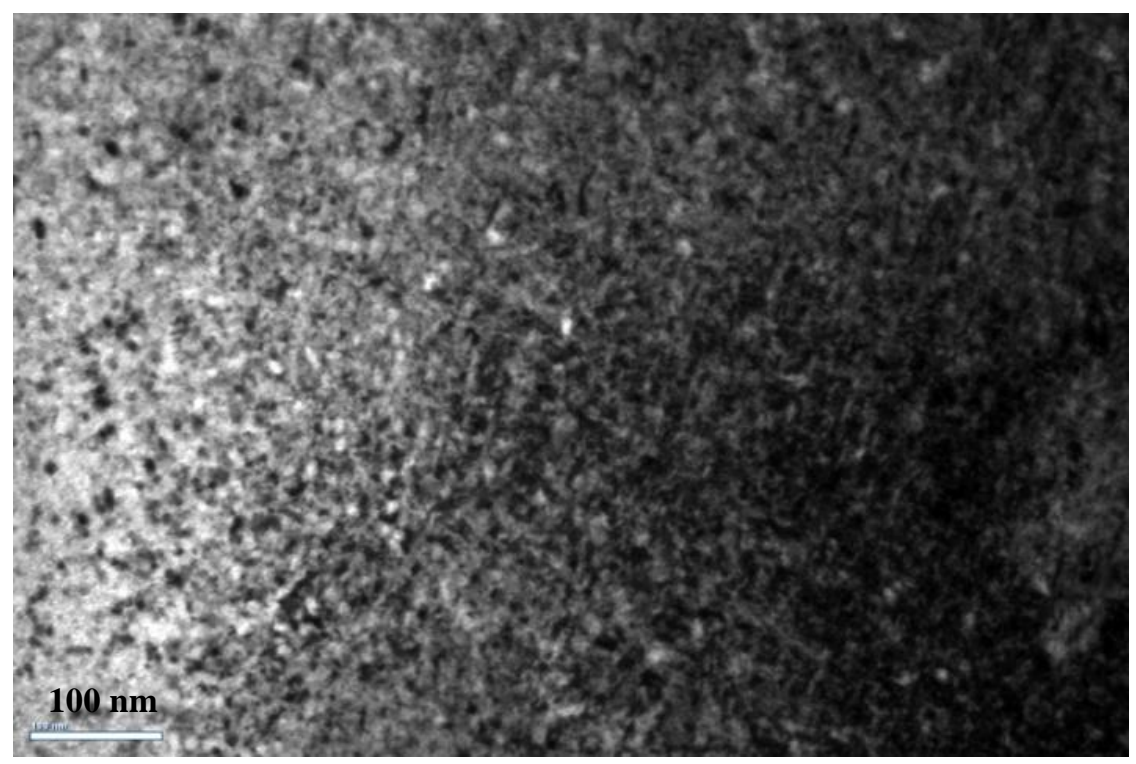

(a)

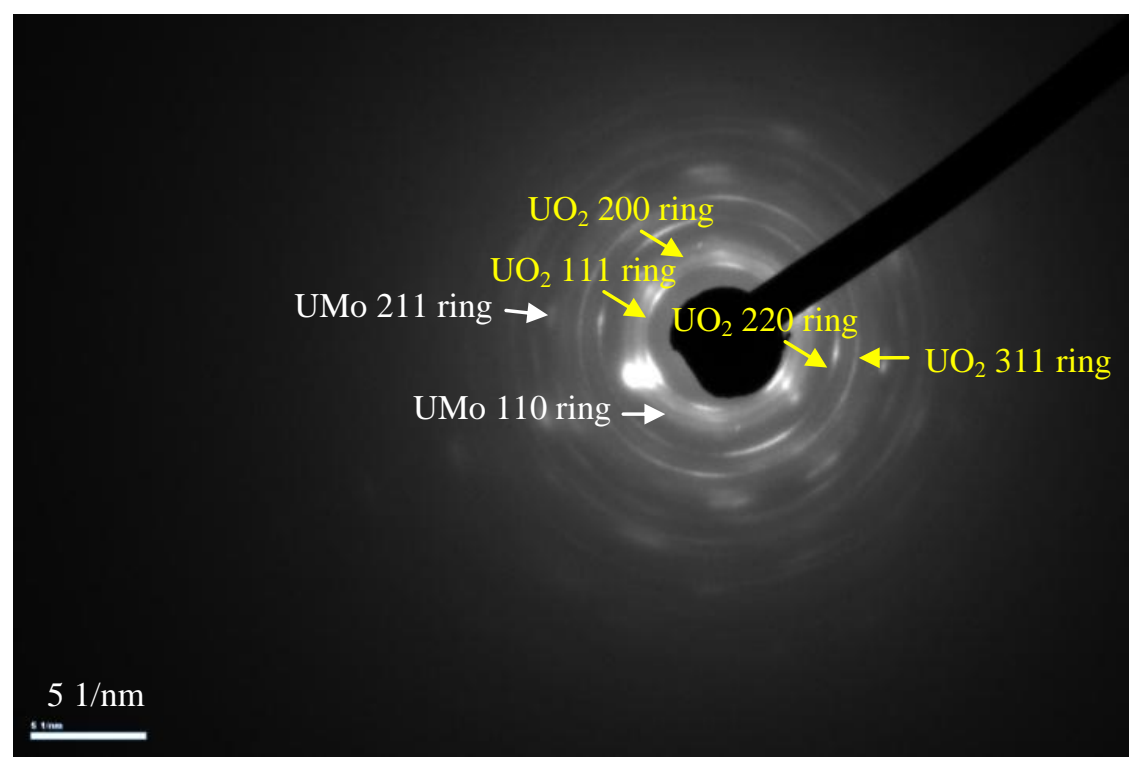

(b)

Figure 4. 


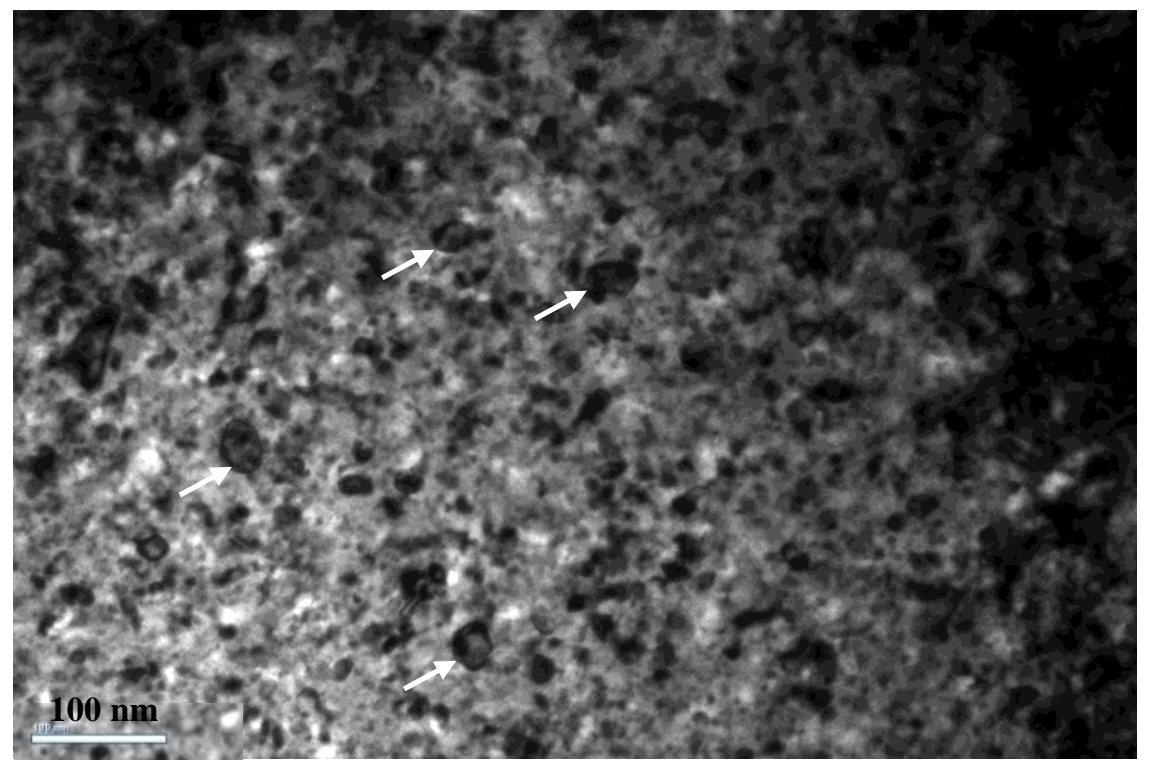

(a)

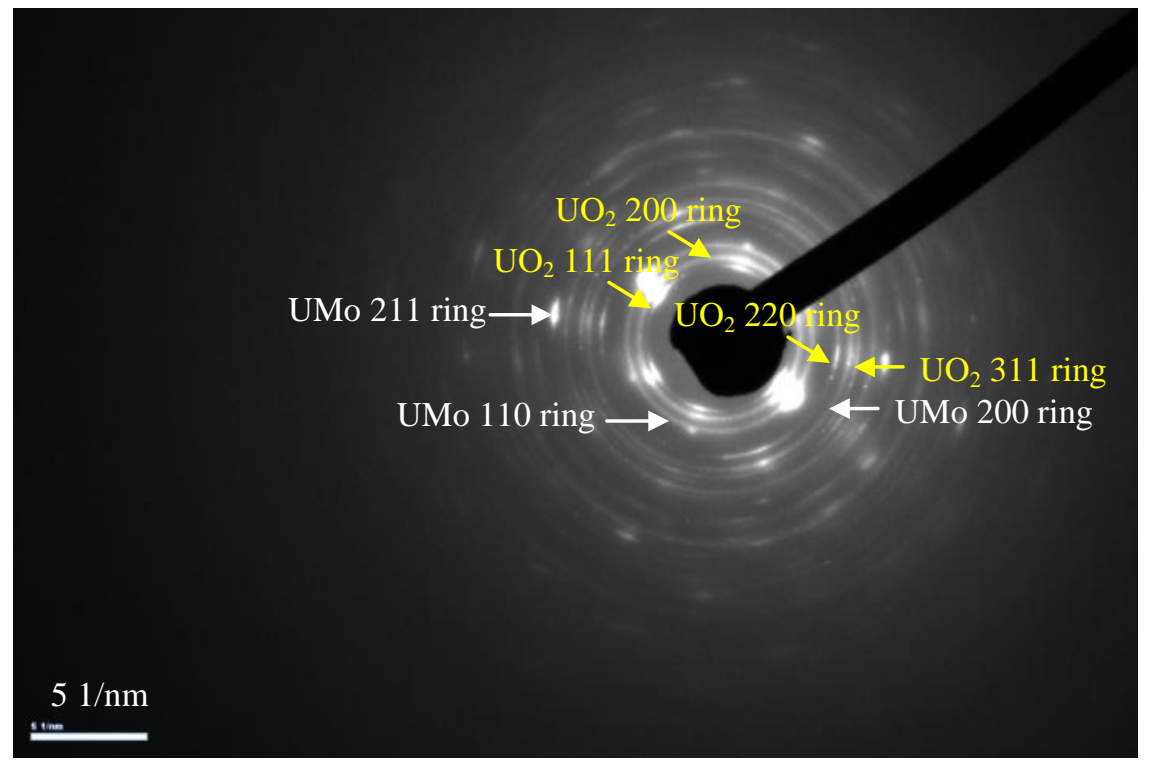

(b)

Figure 5. 


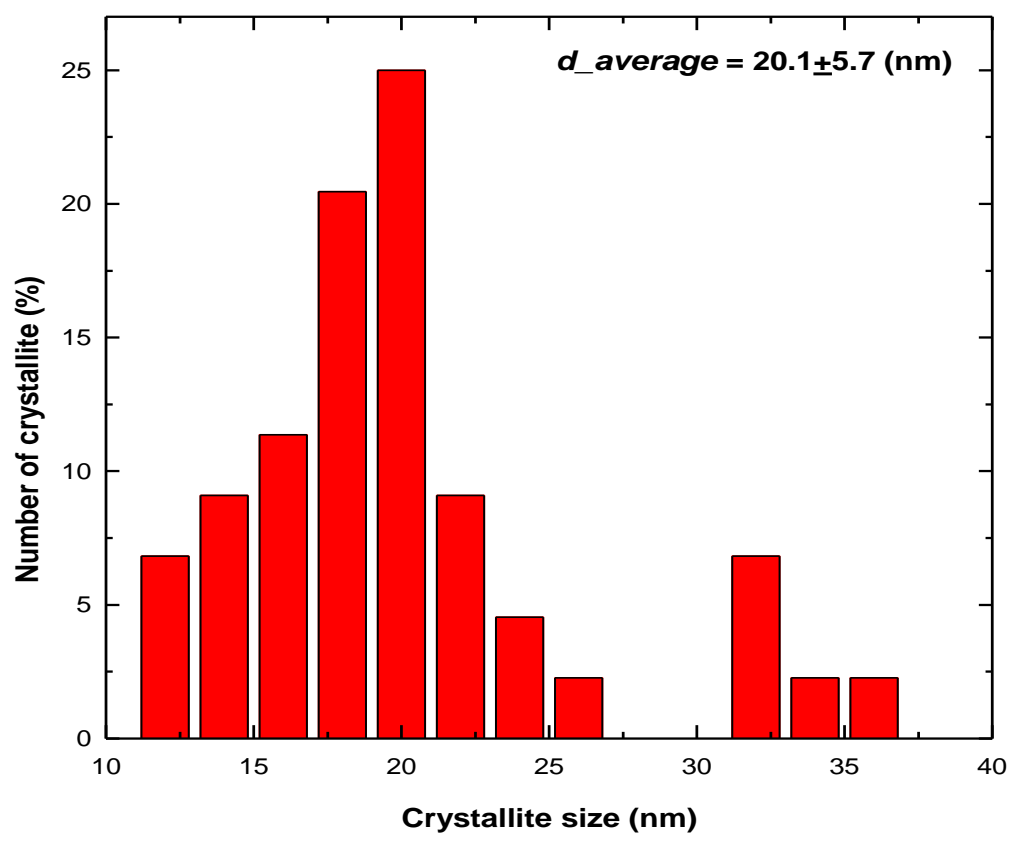

Figure 6. 


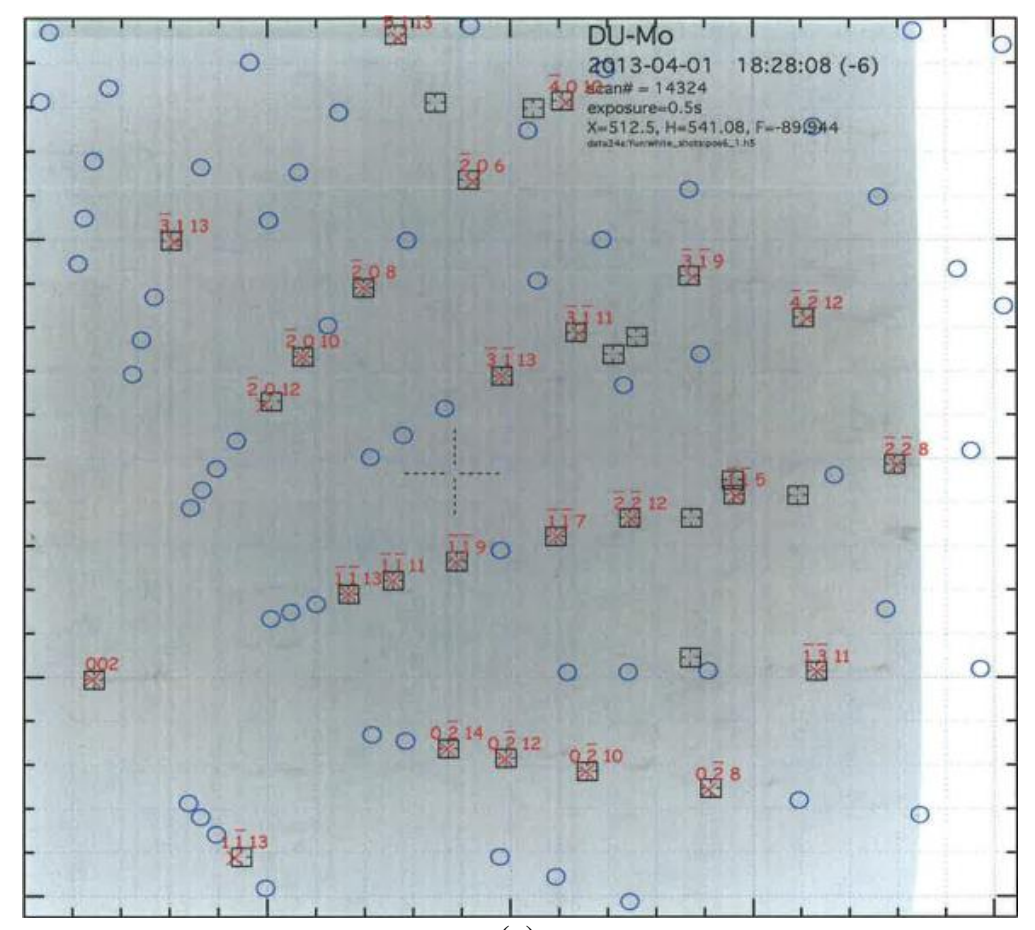

(a)

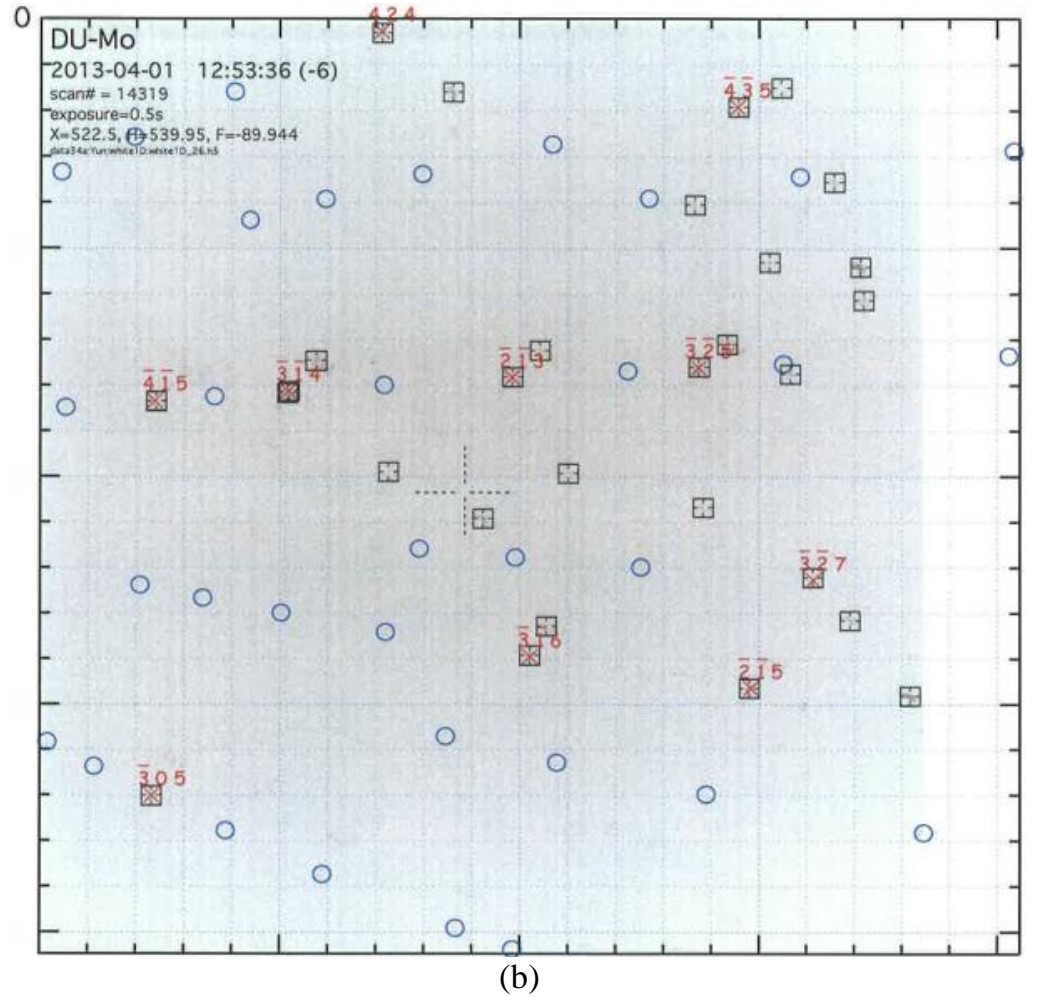

Figure 7. 


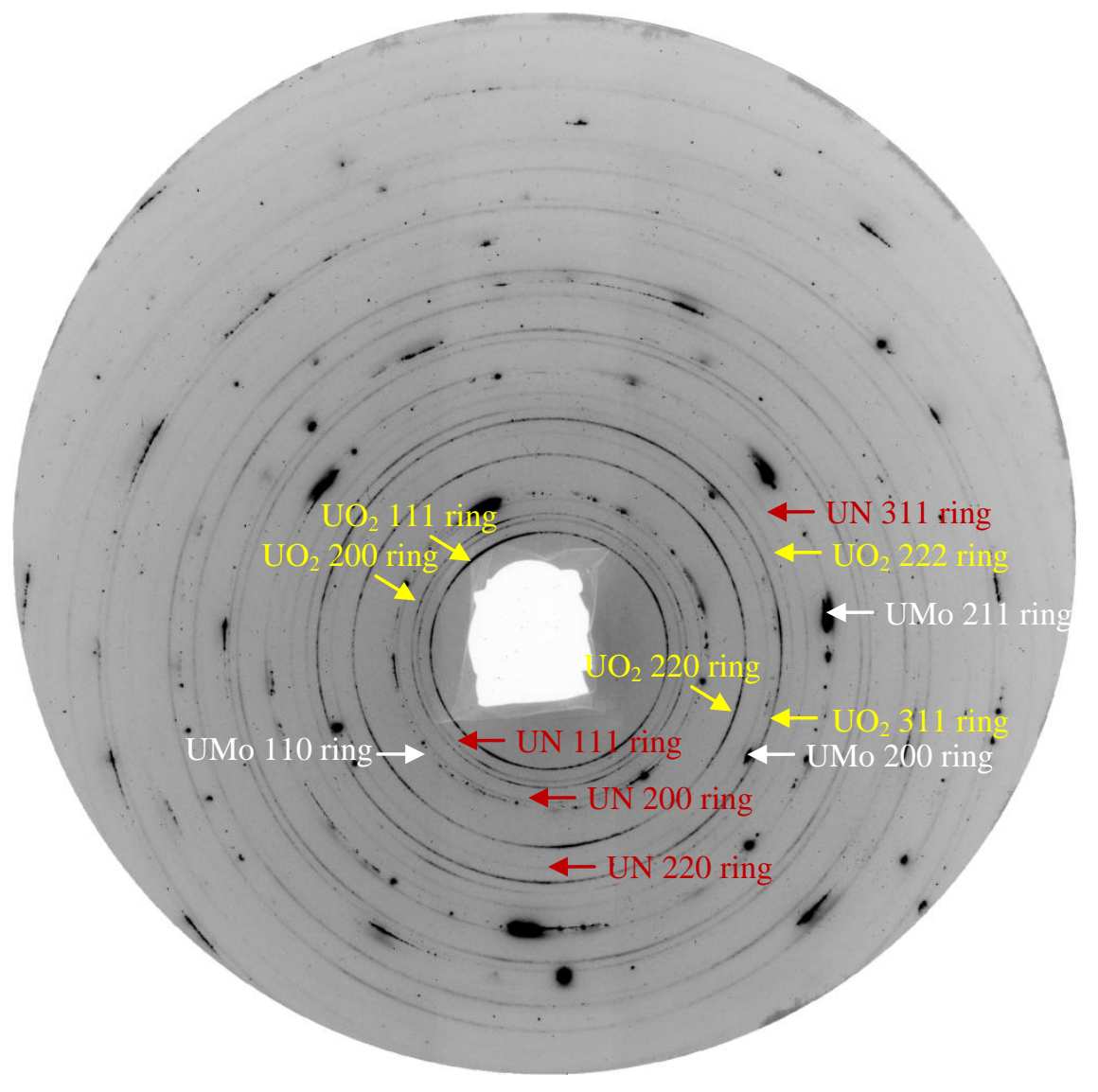

Figure 8. 


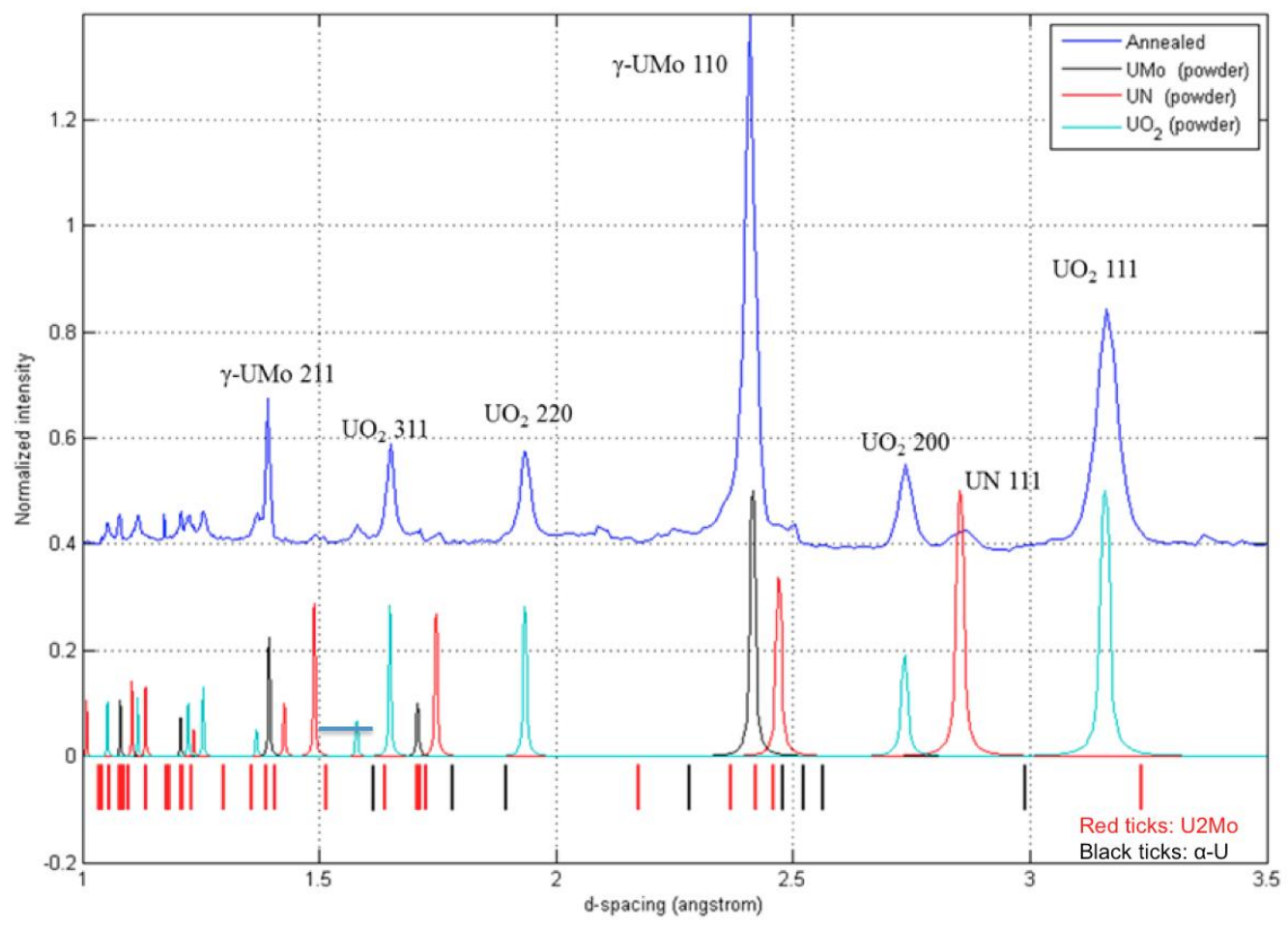

Figure 9. 


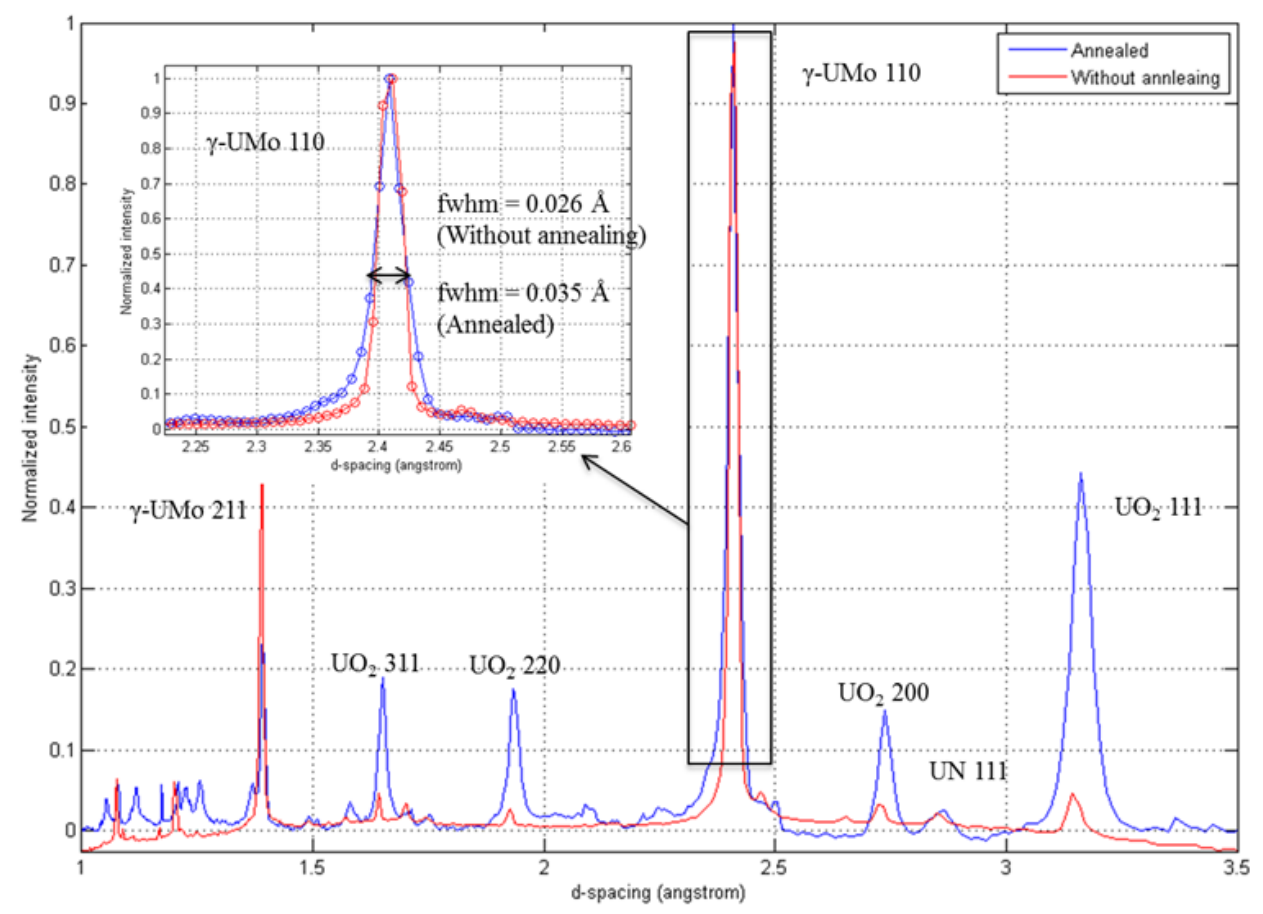

Figure 10. 


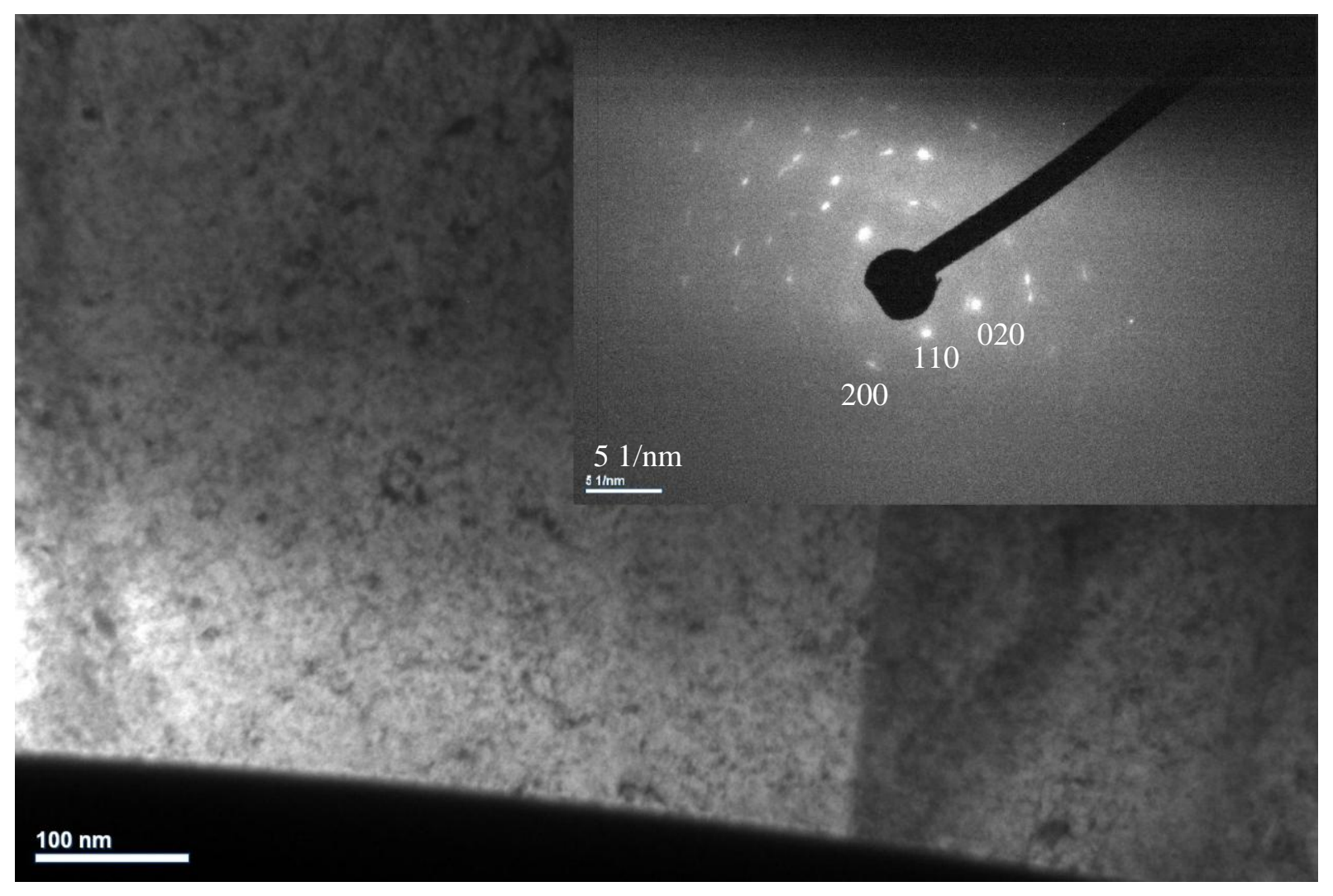

Figure 11. 


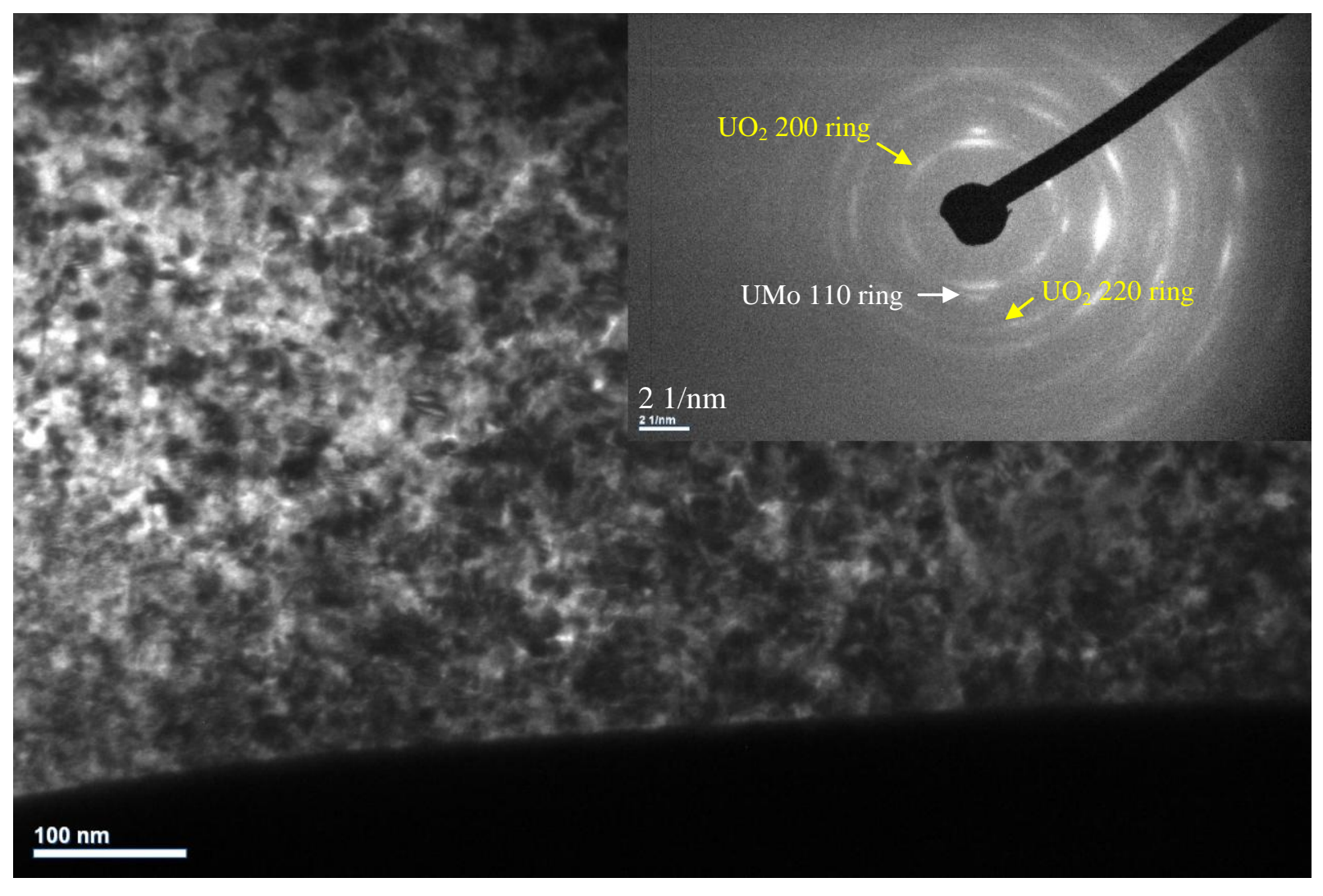

Figure 12. 